Herr Privatdozent Dr. Walther Lob-Bonn:

\title{
ZUR KENNTNIS DER ASSIMILATION DER KOHLENSÄURE.
}

\section{I.}

1. Assimilation der Kohlensäure nennt man bekanntlich die in den grünen Pflanzenteilen unter der Einwirkung des Lichtes stattfindende Zerlegung der atmosphărischen Kohlensăure in Sauerstoff und kohlenstoffreiche Verbindungen, speziell Zucker. Man weiss, dass im allgemeinen die Gegenwart des Blattfarbstoffes Chlorophyll eine Bedingung for den Eintritt dieser Reaktion bildet. Jedoch ist der Vorgang noch nach keiner Seite hin aufgeklărt I). Da das Chlorophyll bisher nur in der lebenden Substanz, und zwar in ibren Assimilationsorganen, den Chloroplasten, wirksam erscheint, so sind alle Versuche, aus den Eigenschaften des isolierten Chlorophylls auf seine physiologischen Funktionen in der Pflanze zu schliessen, fehlgeschlagen. Ferner ist es noch nicht gelungen, die Assimilationstătigkeit mit der Leistung bestimmter Strahlen in Zusammenhang zu bringen. Wir wissen nur, dass in jedem Spektralbezirk weit mehr Energie, als die stărkste Kohlensăureassimilation bedarf, geliefert und die Assimilation durch alle Strahlen, vom aussersten Violett bis zum äussersten Rot, wenn auch mit ungleicher Intensitat, bewirkt wird.

Ein einfaches Verhältnis zwischen optischer Absorption durch das Chlorophyll und Assimilation kann bei der Anzahl der für die letztere notwendigen Faktoren nicht erwartet werden und ist auch nicht beobachtet worden.

Die Ansicht, dass das Chlorophyll selbst das erste Assimilationsprodukt sei, hat sich als irrig erwiesen; far die Vermutung Wiesners, dass das Chlorophyll der Kohlensăure Sauerstoff entreisst, fehlen bisher experimentelle Anhaltspunkte, ebenso für die Ansicht Reinkes, der im Chlorophyll nur einen Sensibilisator sieht. Schliesslich kennen wir niedere Pilze, die auch ohne Chlorophyll assimilieren.

Nicht besser steht es mit unserer Einsicht in die chemischen Vorgănge der Assimilation. Nach von Baeyers ${ }^{2}$ ) Vermutung wird zunachst die Kohlensăure zu Formaldehyd reduziert und der Formaldehyd zu Zucker kondensiert. Formaldehyd ist aber weder als Reduktionsprodukt der Kohlensăure, noch als Zwischenprodukt der Assimilation nachgewiesen worden. Auch die Annahme Erlenmeyers ${ }^{3}$ ), dass die ersten Assimilationsprodukte Ameisensăure und Wasserstoffperoxyd seien, ist nur eine experimentell

1) Die folgenden Angaben entnahm ich Pfeffers Physiologie der Pflanzen, I., Kapitel VII., 2. Auflage (1897). Siehe auch Czapek, Biochemie der Pflanzen, I, Jena (I905).

2) Ber. d. Deutsch. chem. Gesellsch. 3, 66 (1870).

3) Ebenda 10; 634 (I877). nicht gestützte Hypothese. Nach Pfeffer ${ }^{1}$ ) tritt in der assimilierenden Pflanze Wasserstoffperoxyd aberhaupt nicht auf. Liebig ${ }^{2}$ ) sah die organischen Sauren als unmittelbare Assimilationsprodukte, Maquenne Methan, $\mathrm{Crato}^{3}$ ) Benzolderivate als $Z$ wischenprodukte an.

Kurz: der Assimilationsvorgang, einer der wichtigsten Naturprozesse, ist augenblicklich ein Problem, von dessen endgaltiger Losung wir noch weit entfernt scheinen. Dieses Problem hat botanische - morphologische und physio. logische - und physikalisch-chemische Seiten, so dass bei dem reichen Arbeitsprogramm eine Beschrănkung der Fragestellung fär den einzelnen unumganglich geboten ist.

Vor einer Reihe von Jahren begann ich, um die chemische Stofffolge bei der Assimilation aufzuklären, Versuche aber das Verhalten der Koblensaure unter dem Einfluss der stillen Entladung. Ueber den jetzigen Stand der keineswegs abgeschlossenen Arbeit möchte ich kur2 berichten.

2. Die Kohlensaureassimilation ist ein endothermischer Vorgang. Unter den Energieformen, die solche Reaktionen bei gewơhnlicher Tempe. ratur begunstigen, stehen in erster Linie die strahlende Energie und die stille elektrische Entladung. Aus experimentellen Granden und gestatzt auf frahere Versuche anderer Forscher und eigene Erfahrungen wandte ich die letztere, deren Einfluss auf Kohlensăure schon häufig Gegenstand der Forschung war, als Energiequelle an. Theoretische Erwägungen traten hinzu. Bei der engen Beziehung, die nach Goldsteinst), Warburgs 5) und speziell Berthelots ${ }^{6}$ ) Untersuchungen zwischen strah. lender Energie und stiller Entladung besteht, scheint die Wahl der letzteren fár die $\mathrm{Be}$ arbeitung der Assimilationsfrage besonders geeignet. Berthelot hat die Bindung des atmosphă rischenStickstoffes an organische Substanzen, die Zersetzung der Kohlensaure und viele andere Reaktionen beobachtet und gleichzeitig nachgewiesen, dass die in den atmosphärischen Schichten bei heiterem und feuchtem Wetter, sowie die an den Blattoberfláchen aultretenden Potentialdifferenzen zur Erzielung der natürlichen Synthesen genügen, dass ferner, was auch andere Forscher betonten, gerade die bei der stillen Entladung auftretenden Vorgănge vielfach

I) Physiologie der Pflanzen, I., 34I.

2) Die Chemie in ihrer Anwendung auf die Agrikultur, 3o, 9. Aufl. (1876).

3) Physiologie der Pflanzen, I., 341 .

4) Ber. d. Deutsch. chem. Gesellsch. 36, 4042 (I903)

5) Ann. d. Phys. [4] 13, 464 (1903).

6) Compt. rend. 131, 772 (1900). 
an die pflanzlichen Synthesen erinnern. Berthelot schreibt deshalb den atmospharischen Span. nungen eine grosse Rolle $z u$ und sieht in ihnen cinen auch in der Natur wirksamen Faktor der Assimilation.

Ohne hier weiter auf die zahlreichen fraheren Beobachtungen einzugehen - eine vollständige Literaturübersicht wird in den ausfahrlichen Veroffentlichungen gegeben werden - beschränke ich mich im wesentlichen auf die Mitteilung meiner Resultate.

3. Die Stufenfolge der Assimilationsprodukte ist uns, wie bereits erwăbnt, unbekannt; wir besitzen aber für den umgekehrten Vorgang der Zuckerverbrennung physiologische und chemische Anbaltspunkte, und zwar in den Oxyda. tionsvorgăngen des tierischen Organismus und in den Gärungserscheinungen. Von der Mog. lichkeit ausgehend, dass sich das biologische Verhaltnis der pflanzlichen Synthese zu dem tierischen Abbau auch in den physiologischen und chemischen Beziehungen ausgeprăgt fănde, gewann ich fär die Bearbeitung nach beiden Seiten hin gewisse Statzen, in chemischer Hinsicht besonders in der letzten Zeit durch Buchners ${ }^{1}$ ) Arbeiten aber die fermentative Garung und neuerdings durch Stoklasasa) Versuche aber die Kohlehydratverbrennung im tierischen Organismus.

Bei der alkoholischen Gărung ist das erste fassbare Abbauprodukt der Glukose nach Buchner und Meisenheimer ${ }^{3}$ ) die Milchsaure; jedoch spricht die Tatsache, dass Rohrund Traubenzucker stets inaktive Milchsăure geben, für die Richtigkeit der bereits von Wohl4) und $\mathrm{Nef}^{5}$ ) geăusserten Ansicht, dass Methylglyoxal, das um ein Wassermolekül ärmer ist, als die Milchsåure, ein Zwischen. produkt der Milchsaurebildung ist. Ausser der Milchsãure tritt bei der Gărung stets Essigsăure auf. Die genannten Forscher führen die Entstehung der einzelnen Produkte auf die Wirksamkeit hypothetischer spezifischer Enzyme zurück und unterscheiden Zymase, das den Zucker in Milchsăure spaltende Enzym, von der Laktacidase, dem Enzym der Milchsaurespaltung in Alkohol und Kohlensãure, und der Glucacetase, dem Enzym der Zuckerspaltung in Essigsăure.

Stoklasa ${ }^{6}$ ) gewann aus Tierzellen glycolytische Enzyme, die eine Zuckerlosung in Gärung versetzen. Er fand bei der enzymatischen Kohlehydratverbrennung ausser Milch-

I) Ber. d. Deutsch. chem. Gesellsch. 37, 417 (1904); 38, 620 (1905)

2) Ebenda 36, 622, 4058 (1903); 38, 664 (1905)

3) Ebellda 38,621 (1905).

4) von Lippmann, Chemie der Zuckerarten, 1891 (Braunschweig rgo4).

5) Lieb. Ann. 335, 254, 279 (1904).

6) Ber. d. Deutsch, chem. Geselisch. 38, 664 (1905). săure, Alkohol und Kohlensăure bei Sauerstoffzutritt stets Essigsăure und Ameisensăure und bei mehr als 24 standiger Gărung und vollem Luftzutritt auch Wasserstoff. Methan ist noch nicht nachgewiesen worden. Stoklasa macht gleichfalls for jeden Vorgang ein spezifisches Enzym verantwortlich und entwirft auf Grund seiner Versuche ein hypothetisches Schema des Glukoseabbaues durch Atmungsenzyme, das ich in verănderter Form wiedergebe:

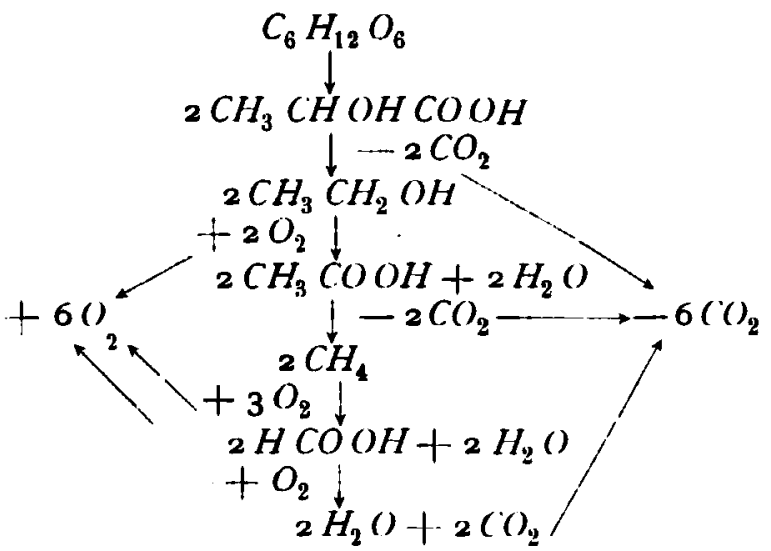

Diese Form ist in Bezug auf den Assimilationsvorgang gewăhlt, um sichtbar zu machen, dass das Volum der bei dem Abbau abgegebenen Kohlensåure mit dem des aufgenommenen Sauerstoffes abereinstimmt.

Das folgende Schema, das ich hierhersetze, beracksichtigt die chemisch durchaus mogliche, intermediăre Bildung von Formaldehyd:

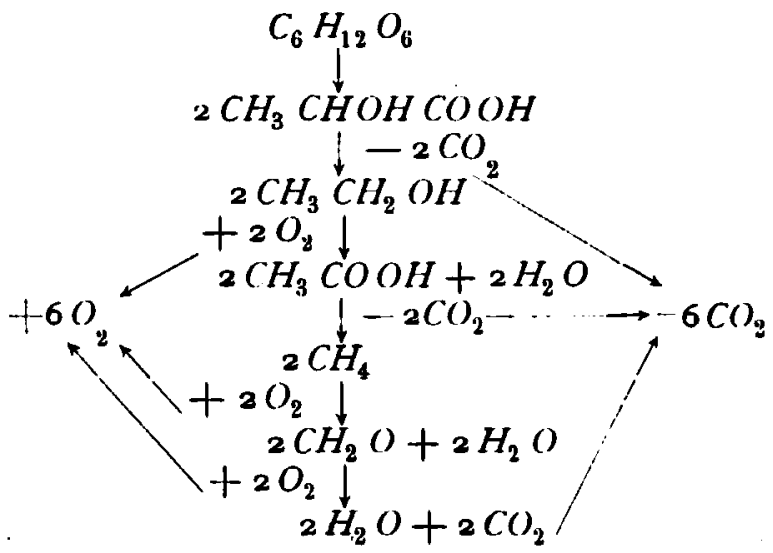

Auch hier sind Sauerstoffverbrauch und Kohlensăureproduktion dem Volumen nach natürlich gleich, nur ist die Verteilung eine andere.

4. Bei dem Versuch, den Assimilations. vorgang auf kunstlichem Wege nachzuahmen, ist die allgemeinste chemische Aufgabe, aus Kohlensăure und Wasser einen Zucker zu erzeugen und von den vielen Moglichkeiten zunächst cine zu realisicren. Die speziellere Aufgabe ist die, diese Synthese auf den von der Natur gewāhlten Wegen zu bewerkstelligen. Es ist nicht unwahrscheinlich, dass einer derselben 
aber die gleichen Zwischenprodukte fahrt, welche die Natur bei dem umgekehrten Vorgang des Abbaues wălılt, d. h. uber Ameisensăure, Essig. săure, Alkohol und Milchsäure.

In der Tat zeigte es sich, dass, wenn man von Kohlensaure und Wasser ausgehend, die zuerst entstehenden Produkte weiter in ent- ersten Kombination - Kohlensäure und Wasser - sämtliche Phasen bis zum Kohlehydrat durchlaufen werden und sich die $Z$ wischenprodukte der Beobachtung hier ebenso entziehen, wie bei der pflanzlichen Assimilation. Aus noch zu erörternden Gränden trat dieser Fall bei meiner Versuchsanordnung nicht ein.

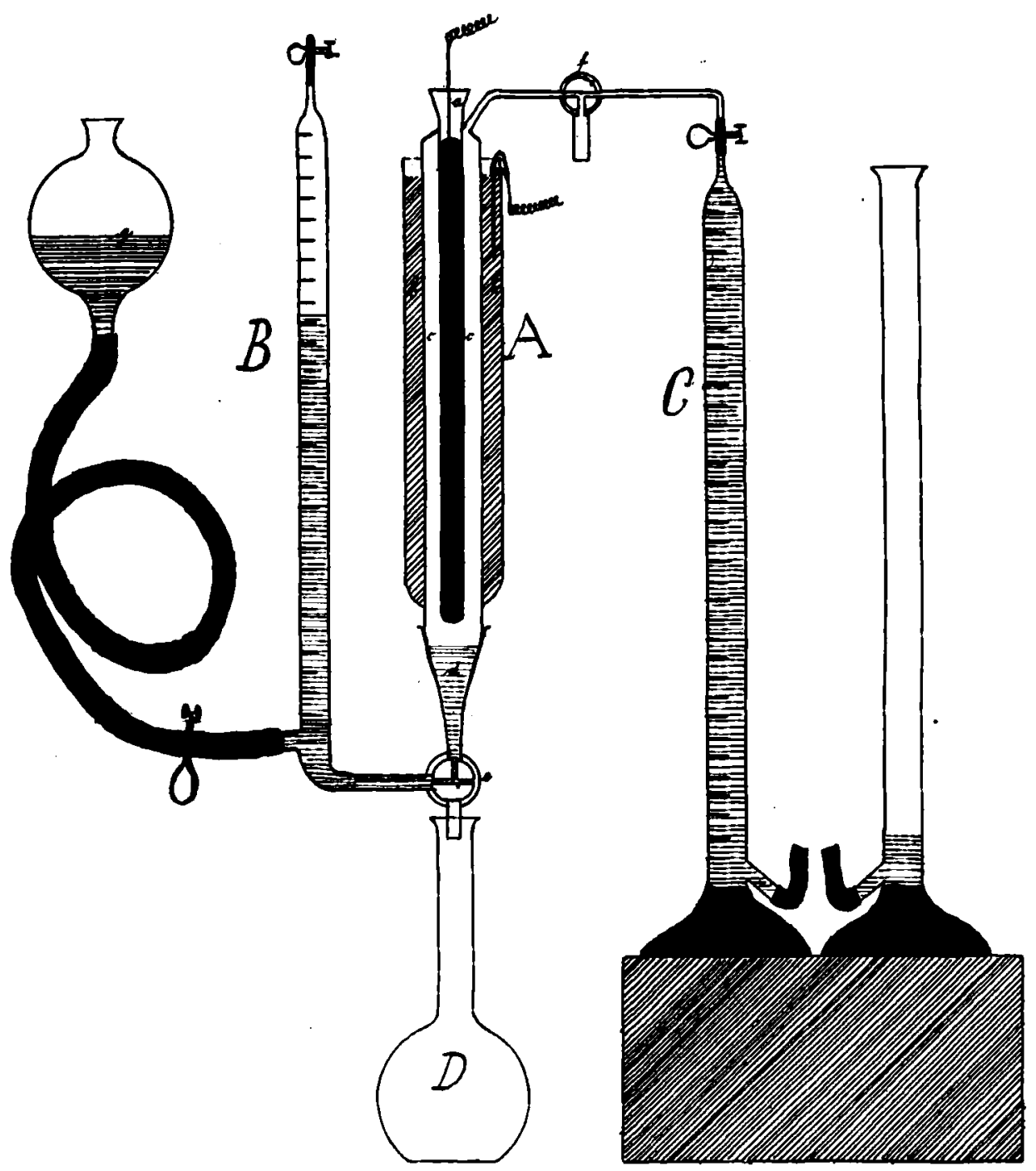

Fig. 242.

$A$ Elektrisator. $a$ Inuenrohr, $b$ Aussenrohr, $c$ Entladungsraum, $d$ Schliffstück, $e$ Zweiweghahu, $f$ Zweiweghahn. - $B$ Flässigkeitsbärette mit Niveauglas $g$ zum Füllen des Elektrisators. $-C$ Hempelsche Gasbarette. $-D$ Messkolben zur Aufuahme der Reaktionsflüssigkeit.

Versuchsanordnung fùr Glimmentladungseaktionen.

sprechender Weise in Reaktion bringt, man die experimentelle Durchführung der Synthese bis zum Kohlehydrat aber die gleichen Phasen soweit ich dieselben bisher gefasst habe - erreichen kann, die bei dem umgekehrten Vorgang, der Kohlehydratverbrennung zu Kohlensăure und Wasser, berahrt werden. Selbstverständlich lag die Moglichkeit vor, dass bereits in der
5. Die letztere ist in ihren wesentlichen Teilen in Fig. 242 skizziert.

Zur Erzeugung der Schwingungen diente ein grosser Ruhmkorff mit einer Maxinalfunkenlange von etwa $150 \mathrm{~mm}$ (Widerstand der Primărwicklung $0,264 Q$, der Sekundärwicklung 10400 Q; Platinunterbrecher, Stromstärke in der Primărspule bei arbeitendem Unterbrecher 
3,5 Amp. im Mittel; bei geschlossenem Unterbrecher 16 Amp.). Als Stromquelle benutzte ich bei den hier zu erwahnenden Versuchen eine Batterie von funf hintereinander geschalteten Akkumulatoren.

Treibt man das Induktorium bei ausgeschaltetem Unterbrecher mit Wechselstrom (Lichtleitung von 110 Volt, etwa $8 \mathrm{Amp}$. in der Primărspule), so andern sich der Charakter der Entladung und die chemischen Effekte. Auf die Ergebnisse der Wechselstromversuche will ich jedoch bei der beschrănkten Zeit gar nicht eingehen, ebensowenig wie auf den Einfluss der Natur der Oscillationen und auf den der Dimensionen des Elektrisators - Punkte, deren Bedeutung vor einiger Zeit de Hemptinne ${ }^{1}$ ) hervorgehoben hat.

Wichtig ist vor allem der Elektrisator, dessen Konstruktion von den bisher gewahlten Apparaten zwar nicht im Prinzip, wohl aber in der Form wesentlich abweicht (Fig. 242).

Der Entladungsraum $c$, ein Glascylinder von etwa $30 \mathrm{~cm}$ Lảnge, tragt, konzentrisch eingeschmolzen, das oben offene, unten geschlossene Glasrohr $a$, das die innere Belegung, Quecksilber oder verdannte Schwefelsăure, aufnimmt. Die Entfernung der Wandungen ist überall genau $2 \mathrm{~mm}$; auf $c$ ist aussen der oben offene Glasmantel $b$ aufgeschmolzen, der gleichfalls mit Schwefelsãure als ăusserer Belegung gefült wird. Durch Platindrăhte wird der Strom der Sekundärspirale den beiden Belegungen zugefahrt. An dem höchsten Punkte des Entladungsraumes sitzt das Kapillarrohr $f$ mit eingeschliffenem Zweiweghahn, der einerseits die Kommunikation mit der Luft, anderseits mit der Hempelschen Burrette $C$ gestattet. Am unteren Ende des Entladungsrohres $c$ sitzt das Schliffstuck $d$, das sich nach unten zu einem Glasrohr mit eingeschliffenem Zweiweghahn $e$ verjungt. Letzterer verbindet entweder das Entladungsrohr mit der Bürette $B$ oder mit dem Kolben $D$, oder schliesslich Bürette mit Kolben.

Die Bürette trăgt seitlich an einem genagend langen Gummischlauch das Niveauglas $g$. Gummischlauch und Bürette sind durch Quetschhăbne verschliessbar.

Zur Fullung des Apparates wird zunáchst der ganze Entladungsraum mittels des Niveauglases mit der Reaktionsflussigkeit, etwa Wasser, gefallt, sodann das Reaktionsgas, etwa Kohlensäure, aus der Hempelschen Barette $C$ bei entsprechenden Hahnstellungen so abergefährt, dass die Reaktionsflussigkeit in die vorber nur teilweise gefallte Barette $B$ gedrangt wird und das innere Rohr $c$ ganz von Gas umgeben ist. Der Quetschhahn des Gummischlauches bleibt wabrend des Versuches geschlossen, der der

I) Bull. de l'Acad. roy. de Belg. [3] 34, 269 (1897).
Barette $B$ offen, auch bleibt die letztere meist mit dem Entladungsraum $c$ in Verbindung, so dass das Gas sich unter etwas höherem Druck als dem jeweiligen Atmosphărendruck befindet, da die Niveaudifferenz der Flossigkeitssăulen in $B$ und $A$ hinzukommt.

Nach Beendigung des Versuches wird das Gas durch Heben des Niveaurohres in die Bürette $C$ zurúckgefahrt, und die gesamte Flossigkeit unter wiederholter Durchspalung des Entladungsraumes in den Kolben $D$ zur Analyse fliessen gelassen.

Dieser kurzen Beschreibung des Apparates sei noch die Bemerkung angefúgt, dass die Temperatur und die Volumveränderung im Versuch in einfacher Weise verfolgt werden konnten und sowohl Gas, wie Flussigkeit qualitativ und quantitativ analysiert wurden.

Auf die Angaben der Analysenmethoden und der qualitativen Reaktionen verzichte ich hier; nur muss ich noch einige Punkte erwăhnen, die teils zu fraheren Versuchen, teils zu den Bedingungen der naturlichen Assimilation in bestimmter Beziehung stehen.

6. Im Gegensatz zu den Anordnungen von Maquenue ${ }^{1}$ ), Berthelot ${ }^{2}$ ), de Hemptinne ${ }^{3}$, Slosse ${ }^{4}$, Losanitsch und Jovitschitsch 5 ) sind nicht nur die zur. Reaktion gelangenden Gase mit der Reaktionsflússigkeit gesaltigt, sondern es wird auch vor allem durch die Gegenwart der Flussigkeit im Entladungsraum unter dem Gase daför gesorgt, das alle in der Flassigkeit loslichen $Z$ wischenprodukte möglichst schnell gelost und dadurch der weiteren Einwirkung der Entladung entzogen werden. In den verdunnten Losungen finden nachweisbare Reaktionen nicht mehr statt; es gelingt, die loslichen Zwischenprodukte $z u$ fixieren, um sie als Ausgangsprodukte neuer Versuche zu verwenden. So wird die bei lang andauernden Versuchen regelmåssig eintretende Polymerisation oder Zersetzung der empfindlichen organischen $Z$ wischenprodukte vermieden.

Ein wesentlicher Unterschied gegenüber den naturlichen Assimilationsbedingungen scheint in den Druckverhältnissen zu liegen. Zwar sind die Flassigkeiten nur mit ihrem von der Temperatur abhăngenden Partialdruck als Dampfe im Entladungsraum, die Gase jedoch befinden sich unter Atmospharendruck, bezw. unter einem noch unwesentlich hoheren Druck. Diese Verschiedenheit, speziell far die Kohlensåure, scheint aber grosser, als sie ist. Denn ist es keine Frage, dass die Kohlensäure an den Assimi-

I) Bull. soc. chim. [2] 39, 308 (1883).

a) Essai de Mécanique chimique II, 366 (1879).

3) Bull. de l'Ac. roy. d. Belg. [3] 34, 269 (1897) und a. a. $O$.

4) Bull. de l'Ac. roy. d. Belg. [3] 35, 547 (1898).

5) Ber. d. Deutsch. chem. Gesellsch 30, I35 (1897). 
lationsorganen der Pflanze in weit hoherer Konzentration vorhanden ist, als ihrem Partialdruck in der Atmosphäre entspricht: nicht allein der Losungsvorgang konzentriert die Kohlensaure an diesen Stellen, sondern nach den interessanten Beobachtungen von Sieg. fried 1) wohl vor allem die chemische Bindung der Kohlensăure an amphotere Eiweisskorper. Ich musste, um in meinen kleinen Apparaten, deren Grosse durch die elektrische Anlage begrenzt war, brauchbare Stoffausbeuten zu erhalten, die Menge der Reaktionskomponenten mőglichst gross wăhlen. Deshalb und um spater gesondert den Einfluss verdunnender Medien zu untersuchen, benutzte ich vorerst reine Gase unter den erwahnten Drucken.

Bezaglich der Verschiebung sămtlicher Versuchsbedingungen, welche die Uebertragung des chemischen Vorganges aus der organisierten lebenden Zelle in den kunstlichen Laboratoriumsapparat notwendig mit sich fahrt, soll ausser der bereits erorterten Wabl der stillen Entladung an Stelle des Lichtes als Energiequelle noch ein Punkt besonders hervorgehoben werden: das Fehlen der Katalysatoren oder Enzyme. Zweifellos spielen die letzteren bei der Assimilation eine grosse Rolle. Aber ihre schon durch unsere Unkenntnis erzwungene Abwesenheit bei meinen Versuchen ist dem Ziele der Untersuchung vorlauufig nicht ungünstig. Wirken die Enzyme in der Natur tatsachlich rein katalytisch -- es liegen keine Anhaltspunkte vor, das zu bezweifeln -, so besteht ibre Wirksamkeit lediglich in der Veranderung und for die Assimilationsvorgänge zweifellos in der Erhohung der Reaktionsgeschwindigkeiten. Dann werden sich die Reaktionen, sofern sie unter den Versuchsbedingungen moglich sind, auch ohne Katalysatoren, nur sehr langsam, abspielen. Dadurch ist einerseits die Wahrscheinlichkeit, die Zwischenprodukte zu fassen, trotz der zu erwartenden schlechten Stoffausbeuten erhoht, anderseits wird die experimentelle Aufgabe, die Wirkungsweise verschiedener Katalysatoren anorganischer, organischer und enzymatischer zu ermitteln, nicht vorzeitig kompliziert.

\section{II.}

Bei meinen Versuchen bin ich noch nicht aller Schwierigkeiten - es handelt sich zumeist um analytische - Herr geworden. In dieser Richtung unabgeschlossene Versuchsreihen lasse ich bei Seite.

I. Koblensaure und Wasser. Bei der Einwirkung der stillen Entladung auf feuchte Kohlensaure entstehen, wie bereits bekannt ist ${ }^{2}$ ),

1) Hoppe-Seylers Zeitschr. f. physiol. Chemie 44. 85 (1905).

2) Berthelot, Essai de Mécanique chimique 2 , 377 (1879); Losanitsch und Jovitschitsch, Ber. d.
Kohlenoxyd, Ameisensăure, Wasserstoffperoxyd und Sauerstoff; Formaldehyd tritt nicht auf. Von den für die Ameisensäurebildung morglichen Reaktionen:

$$
\begin{aligned}
& \text { I. }{ }_{2} \mathrm{CO}_{2}+2 \mathrm{H}_{2} \mathrm{O}=2 \mathrm{HCOOH}+\mathrm{O}_{2}, \\
& \text { II. }\left\{\begin{array}{l}
2 \mathrm{CO}_{2}=2 \mathrm{CO}+\mathrm{O}_{2}, \\
2 \mathrm{CO}_{2} \mathrm{H}_{2} \mathrm{O}=2 \mathrm{HCOOH},
\end{array}\right.
\end{aligned}
$$

stellt die zweite Form den Vorgang dar. Der Zerfall der Kohlensauure ist stets der primare Prozess. Unterbricht man nåmlich den Versuch nach kurzer Zeit, so ist noch keine Spur Ameisensăure entstanden, und das Verhaltnis des Kohlenoxydvolumens zu dem des Sauerstoffes ist genau $2: 1$. Bei fortgesetztem Versuch andert sich das Verhaltnis und es findet sich Ameisensaure. Ihre Menge ist aber immer sehr gering. Denn bei Atmosphărendruck tritt, wenn die Zersetzung der Kohlensaure erst wenig vorgeschritten ist, Gleichgewicht ein (bei 3 bis $10 \mathrm{~mm}$ Quecksilber zerfállt nach Versuchen von Normann Collie ${ }^{1}$ ) die Kohlensaure bis zu $70 \%$, und dieses Gleichgewicht wird durch die Ameisensăure- und Peroxydbildung nur langsam zu Gunsten eines weiteren Zerfalles der Kohlensăure gestört. In der Natur aber wird der Sauerstoff sofort aus dem Reaktionssystem durch sein Entweichen in die Atmosphäre, so weit er nicht in Oxydationsvorgăngen verbraucht wird, entfernt und so das Gleichgewicht stets in einem der Kohlensăurespaltung günstigen Sinne verschoben. Aus diesen Grunden ist die Kohlensâure ein ungeeignetes Ausgangsmaterial. Es ist geboten, entweder direkt von sauerstofffreiem Kohlenoxyd auszugehen oder der Kohlensăure einen Depolarisator für Sauerstoff sogleich zuzusetzen. Beide Wege wurden eingeschlagen.

2. Kohlenoxyd und Wasser. Maquenne ${ }^{2}$ ) hat bei der Einwirkung der Entladung ausser Ameisensăure stets Kohlensăure und Wasserstoff erhalten. Diese Beobachtung ist richtig, aber nicht vollstăndig: es entsteht neben der Ameisensăure Formaldehyd. Es muss also auch aus Kohlensaure und Wasser Formaldehyd entstehen, sobald man durch Entfernung des Sauer. stoffes für eine Storung des Gleichgewichtes und eine Fortsetzung der Kohlenoxydbildung sorgt. Die Bildung des Formaldehyds verlăuft nach der Reaktion:

$$
\mathrm{CO}+\mathrm{H}_{2}=\mathrm{CH}_{2} \mathrm{O} \text {. }
$$

Der Wasserstoff ist das Spaltungsprodukt des Wassers durch Kohlenoxyd, das in Kohlen. sâure abergeht.

$$
\mathrm{CO}+\mathrm{H}_{2} \mathrm{O}=\mathrm{CO}_{2}+\mathrm{H}_{2} \text {. }
$$

Stoklasa hat bei lang fortgesetzter Gărung Wasserstoff erhalten. Es liegt nahe, anzunehmen,

Deutsch. chem. Gesellsch. 30, I35 (1897); Löb, Sitzungsbericht d. niederrhein. Gesellsch. für Natur u. Heilkunde I903 u. a.

1) Journ. of chem. Soc. 465, 1063 (1901).

a) Bull. soc. chim. [2] 39, 308 (1883). 
dass auch hier das Endprodukt der Garung, die Kohlensaure, weiter zum Teil in Sauerstoff und Kohlenoxyd gespalten wird und letzteres unter Regencration der Kohlensăure die Wasserstoffbildung bewirkt.

Das Kohlenoxyd ist der Ausgangspunkt zweier für den Assimilationsvorgang wichtiger Substanzen, des Formaldehyds und der $\Lambda$ meisensäure, die demnach náchst dem Kohlenoxyd als erste Reduktionsprodukte der feuchten Kohlensåure angesehen werden müssen.

In dem Gasgemisch nach Beendigung des Versuches sind Kohlensaure, Kohlenoxyd und Wasserstoff. Um die Wechselwirkung dieser Gase unter dem Einfluss der Entladung genauer kennen zu lernen, wurde das Verhalten von feuchter Kohlensaure und Wasserstoff, sowie von feuchtem Kohlenoxyd und Wasserstoff unter. sucht.

3. Kohlensaure, Wasserstoff und Wasser. Nach Versuchen von Berthelot') bildet sich durch stille Entladung in einem Gemisch der beiden Gase, wenn Wasserstoff in grossem Ueberschuss zugegen ist, ein Gemenge von Polymeren des Formaldehyds, teils in Wasser löslichen, teils unlöslichen, das die Fehlingsche Losung nicht reduziert, wohl aber Silbernitrat, und bei höherer Temperatur unter Karamelgeruch verkohlt. Nebenbei entsteht Essigsăure. Berthelot spricht die Aldehydpolymeren als kohlehydratahnliche Stoffe an, jedoch ohne bestimmte Anhaltspunkte für diese Annahme mitzuteilen.

Bei meiner Versuchsanordnung in Gegenwart des die Zwischenprodukte absorbierenden Wassers entsteht keine Spur solcher Stoffe, es finden sich lediglich Kohlenoxyd, Formaldehyd und Ameisensäure als Reaktionsprodukte. Die Ameisensäuremenge ist gegenuber der in den Versuchen mit feuchtem Kohlenoxyd ohne Wasserstoff entstandenen gestiegen, so dass wahrscheinlich neben der Reaktion:

$$
\mathrm{CO}+\mathrm{H}_{2} \mathrm{O}=\mathrm{HCOOH}
$$

auch die Vercinigung von Kohlensäure und Wasserstoff

$$
\mathrm{CO}_{2}+\mathrm{H}_{2}=\mathrm{HCOOH}
$$

direkt zur Ameisensăure zu führen vermag. Die Bildung der lctzteren aus Kohlensäure und Wasserstoff haben bereits Losanitsch und Jovitschitsch") beobachtet, die des Formalclehyds dagegen nicht.

4. Kohlenoxyd, Wasserstoff und Wasser. Bei der Einwirkung des Effluviums auf Kohlenoxyd und Wasserstoff entstehen nach Berthelots Angaben gleichfalls kohlehydrat. ähnliche Stoffe, die bei verminderter Wasserstoffmenge den Oxycellulosen nahe stehen sollen.

f) Compt. rend. 126, 609 (1898).

2) Ber. d. Deutsch. chem. Ges. 30, I35 (I897).
Slosse ${ }^{1}$ ) will aus dem Gemenge dieser Gase einen kristallisierten Zucker erhalten baben. Seine experimentellen Angaben geben keinen genugenden Einblick in die Versuchsanordnung; mir ist die Darstellung eines Zuckers unter den verschiedensten Bedingungen, auch bei Ausschluss von Wasser, niemals gegluckt. Jedoch ist, da Formaldehyd entsteht, bei Fehlen des Wassers die Möglichkeit seiner Polymerisation, die Losanitsch und Jovitschitsch schon beobachteten, vorhanden.

Mir lieferte die Reaktion abermals nur Formaldehyd und Ameisensaure, und trotz der Gegenwart des Wasserstoffs auch Kohlensăure in ganz betrăchtlicher Menge durch die Zersetzung des Wassers durch Kohlenoxyd.

Bei dieser Kombination tritt der Formaldehyd gegenaber der Ameisensauure sehr in den Vordergrund, ein Zeichen dafur, dass die Vereinigung des Kohlenoxyds mit Wasserstoff unter diesen Bedingungen schneller verlauft als mit Wasser.

5. Kohlensaure, Wasser und Sauerstoffdepolarisator. Die zweite, der natürlichen Synthese mehr angepasste Kombination besteht in der Verwendung feuchter Koblensăure unter Zusatz eines den Sauerstoff chemisch aus dem System bringenden Stoffes, da die mechanische Entfernung des Sauerstoffs durch die Apparatur ausgeschlossen ist. Als Depolarisatoren wurden Aldehyde, wic Benzaldehyd und Salicylaldehyd, und leicht oxydable Stoffe, wie Pyrogallussåure, benutzt; alle mit dem gleichen Effekt. Im resultierenden Gasgemisch ist kein Sauerstoff, es tritt eine reichlichere Spaltung der Kohlensäure in Kohlenoxyd und damit eine stărkere Bildung von Ameisensture und Formaldehyd auf.

Genau die gleiche Rolle, wie diese leicht oxydabeln Korper, spielt nun das Chlorophyll unter dem Einfluss der stillen Entladung. Nach Beendigung des Versuches war das Gasgemenge stets sauerstofffrei und die Ausbeute an Kohlenoxyd und Ameisensäure erheblich gewachsen. Wie viel Sauerstoff ein bestimmtes Quantum Chlorophyll zu binden vermag, ist noch nicht entschieden. Jedoch gibt die Tatsache der Sauerstoff-Fixierung durch Chlorophyll auch unab. hángig von den quantitativen Beziehungen wichtige Fingerzeige for die physiologische Rolle des Chlorophylls.

6. Reduktionsprodukte der Kohlensäure, dic für die Assimilation bei diesen Versuchen in Frage kommen, sind Ameisensäure und Formaldehyd. Es war deshalb notwendig, ibr Verhalten in Gegenwart von Wasser bei der stillen Entladung weiter zu verfolgen.

I) Bull. de l'Ac. roy. d. Belg. (3) 35, 547 (1898). 
Formaldehyddampf, mit Wasserdampf gemischt, zerfallt, in etwas modifizierter Versuchsanordnunguntersucht, vorwiegendin Kohlenoxyd und Wasserstoff, die Komponenten seiner Bildung. Ausserdem tritt in kleinerem Betrage Kohlensaure aus Kohlenoxyd und Wasser und durch Reduktion des Formaldehyds Methan auf:

$$
\mathrm{CH}_{2} \mathrm{O}+2 \mathrm{H}_{2}=\mathrm{CH}_{4}+\mathrm{H}_{2} \mathrm{O} \text {. }
$$

Ameisensäuredampf, mit Wasserdampf gemischt, verhalt sich ganz ahnlich. Hauptsăchlich tritt ein Zerfall in Wasserstoff und Kohlensaure, die, wie erwăhnt, auch zu Ameisensăure zusammentreten, ein. Ferner entsteht aus der Kohlensăure Kohlenoxyd, das mit dem Wasserstoff Formaldehyd bildet, der weiter zum geringen Betrage zu Methan reduziert wird. Trioxymethylenbildung aus Formaldehyd zeigte sich, wenn Formaldebyd- und Wasserdampf ohne Einwirkung der Entladung unter sonst gleichen Bedingungen lăngere Zeit in Berührung blieben, ebenso wie unter dem Einfluss der elektrischen Schwingungen. Sonst wurde weder bei den Formaldehyd- noch den Ameisensăureversuchen das Auftreten polymerer Verbindungen beobachtet.

Als neues beachtenswertes Reduktionsprodukt ist Methan hinzugekommen, dessen Teilnahme an der Assimilation nach Stoklasas Vermutung nicht von der Hand zu weisen ist. Unterwirft man Methan und Wasser der stillen Entladung, so findet Abspaltung von Wasserstoff unter gleichzeitiger Kohlenoxydbildung statt, wahrscheinlich nach der Reaktion:

$$
\mathrm{CH}_{4}+\mathrm{H}_{2} \mathrm{O}=\mathrm{CO}+3 \mathrm{H}_{2} \text {. }
$$

Damit ist wieder Gelegenheit zur Kohlensãure -, Formaldehyd- und Ameisensäurebildung gegeben, die sich, die beiden letzteren reichlich, vorfinden.

Liegt das Methan auf dem Wege, der von der Kohlensăure zum Kohlehydrat fährt, so kann eine weitere Synthese nur unter neuer Beteiligung der Kohlensăure, bezw. ihrer sauerstoffhaltigen Reduktionsprodukte eintreten, etwa nach den Gleichungen:

$$
\begin{aligned}
& \text { I. } \mathrm{CH}_{4}+\mathrm{CO}_{2}=\mathrm{CH}_{3} \mathrm{COOH} . \\
& \text { II. } \mathrm{CH}_{4}+\mathrm{HCOOH}_{\mathrm{CH}} \mathrm{CH}_{3} \mathrm{COOH}+\mathrm{H}_{2} \text {. } \\
& \text { III. } \mathrm{CH}_{4}+\mathrm{CH}_{2} \mathrm{O}=\mathrm{CH}_{3} \mathrm{CH}_{2} \mathrm{OH} \text {. }
\end{aligned}
$$

Die Versuche, diese Vorgänge zu realisieren, sind noch nicht abgeschlossen.

Jedoch lásst sich schon aus der von Maquenne ${ }^{1}$ ) und de Hemptinne ${ }^{2}$ ) festgestellten Tatsache, dass Essigsaure zum Teil in Methan und Kohlensăure zerfăllt, mit Sicherheit auch der Eintritt des entgegengesetzten Prozesses der Essig. salurebildung folgern. Auch hat Berthelot ${ }^{3}$ ) durch direkte Vereinigung von Kohlensăure und

1) Bull. soc. chim. [2] 39, 306 (1883).

2) Zeitsch. f. physik. Chemie 25, 284 (1898).

3) Compt. rend. 126, 609 (1898).
Wasserstoff unter dem Einfluss der Entladung Essigsaure erhalten. Ferner ist von Losanitsch und Jovits $\operatorname{chits}^{-1} \operatorname{ch}^{1}$ ) nachgewiesen, dass Methan und Kohlenoxyd zu Acetaldehyd zusammentreten, eine Reaktion, die der Essigsäuresynthese aus Methan und Kohlensăure ganz analog ist.

Wie die Ameisensăure, so ist auch die Essigsäure im Pflanzenreich verbreitet; ebenso findet sie sich als Verbrennungsprodukt der Kohlehydrate bei der Gărung und in tierischen Saften, so dass sie jedenfalls als $Z$ wischenprodukt des Assimilationsvorganges Berácksichtigung verdient.

Durch weitere Reduktion der Essigsăure entsteht der Aethylalkohol, der sich, wie erwahnt, auch vielleicht aus Formaldehyd und Methan, ohne die Essigsăure zu berühren, bildet. Es ist wohl kein $Z$ weifel, dass unter den mog. lichen $Z$ wischenstufen der Assimilation nach unseren heutigen Erfahrungen der Alkohol eine hervorragende Stellung einnimmt. In welchem Sinne er als Reaktionsprodukt der feuchten Kohlensăure aufgefasst werden kann, ist soeben gezeigt worden. Far seine Rolle als Phase des von der Kohlensåure zum Kohlehydrat führenden Vorganges spricht in erster Linie die Tatsache, dass er ein regelmăssiges Produkt der Gărung des Zuckers ist. Ferner findet er sich in nicht gegorenen Pflanzensäften ${ }^{2}$ ), teils in freiem $\mathrm{Zu}$ stande (in Heracleumfrachten), teils in atherischen Oelen als Esterradikal. In gleicher Weise dürte der Methylalkohol, dessen direkte Synthese durch die Entladung aus Koblenoxyd und Wasserstoff:

$$
\mathrm{CO}+2 \mathrm{H}_{2}=\mathrm{CH}_{3} \mathrm{OH}
$$

Slosse ${ }^{3}$ ) erwähnt, als Etappe auf den vielen verschiedenen, in der Natur moglichen und grossenteils wohl auch benutzten Wegen auftreten.

Jedoch habe ich die Schwierigkeit, in meiner Versuchsanordnung speziell die Bildung und Menge des Aethylalkohols festzustellen, noch nicht aberwunden, so dass ich schliesslich, bier vorläufig eine Lucke aberspringend, als Ausgangsprodukt der nächsten Versuche direkt den Aethylalkohol wăhlte, der als ein Endprodukt der alkoholischen Gärung, als $Z$ wischenprodukt der tierischen Kohlehydratverbrennung, jeden. falls ein besonders wichtiger Faktor des umgekehrten Prozesses, der natürlichen Kohlehydratsynthese, ist. Es galt, zu ermitteln, ob ein Zusammenschluss von Kohlensäure und Alkohol zu Milchsaure, Methylglyoxal oder Zucker moglich ist:

I) 1. c

2) Ebermayer, Physiologische Chemieder Pflanzen 1, 126 (Berlin 1882).

3) Bull d. YAc. roy. d. Belg. 35, 547 (1898). Siehe auch $M$ a quenne, Compt. reud. 101, 1067 (1886): über den Befund von Methylalkohol im Destillate von Pflanzenblăttern. 
I. $\mathrm{CH}_{3} \mathrm{CH}_{2} \mathrm{OH}+\mathrm{CO}_{2}=\mathrm{CH}_{3} \mathrm{CHOHCOOH}$.

II. $\mathrm{CH}_{3} \mathrm{CH}_{2} \mathrm{OHI}+\mathrm{CO}_{2}=\mathrm{CH}_{3} \mathrm{COCOH}+\mathrm{H}_{2} \mathrm{O}$. III. ${ }_{2} \mathrm{CH}_{3} \mathrm{CH}_{2} \mathrm{OH}+{ }_{2} \mathrm{CO}_{2}=\mathrm{C}_{6} \mathrm{H}_{12} \mathrm{O}_{6}$.

7. Alkohol und Wasser. Wasseriger Alkohol gibt bei Ausschluss von Kohlensaure unter dem Einfluss der stillen Entladung keine Spur eines Kohlehydrates. Der Alkohol zersetzt sich teilweise in gesattigte und ungesättigte Kohlenwasserstoffe, Kohlenoxyd, Wasserstoff und sehr wenig Kohlensãure. Natarlich treten durch weitere Reaktion dieser Gase unter sich oder mit Wasser wieder Formaldehyd und Ameisensăure auf; gleichzeitig wird ein Teil des Alkohols zu Acetaldehyd oxydiert.

Alkohol, Wasser und Kohlensăure. In Gegenwart von Kohlensäure aber verlăuft der Versuch ganz anders. Wahrend bei ihrem Ausschluss in 16 Stunden nur $9,6 \mathrm{ccm}$ Kohlensáure entwickelt wurden - die Hauptmenge des aus dem Alkohol stammenden Sauerstoffs wird zu seiner Oxydation zu Acetaldehyd, zur Formaldebyd-, bezw. Koblenoxydbildung verbraucht -, sind nunmehr in der gleichen Zeit $193 \mathrm{ccm}$ Kohlensăure verschwunden; Acetaldehyd ist, wenn überhaupt, nur in Spuren entstanden, wakhrend die Spaltung des Alkohols in Kohlen. oxyd, Wasserstoff und Kohlenwasserstoff wohl auftritt und die Entstehung von Formaldehyd und Ameisensăure veranlasst. Die Menge des Kohlenoxyds, das zum Teil aus der Kohlensaure stammt, ist erheblich gestiegen. Die Reaktionsflussigkeit aber zeigt sämtliche Reaktionen eines Zuckers an. Beim Abdampfen der Losung auf dem Wasserbad hinterbleibt wenig sauer auf Lackmus reagierender Sirup, der in Wasser wieder gelost die Polarisationsebene nicht dreht, mit Natronlauge Gelbfărbung, mit Resorcin oder Diphenylamin und Schwefelsăure Rotfărbung, mit a-Naphtol und Schwefelsăure die charakteristische Farbreaktion gibt, Fehling sche Losung beim Erwärmen kräftig reduziert und auf dem Wasserbade mit Phenylhydrazin alsbald ein in Nadeln aus verdanntem Alkohol kristallisierendes Osazon vom Schmelzpunkt 160 bis $164^{\circ}$ liefert, das sich gegen $180^{\circ}$ unter Aufschăumen zersetzt. Genauere Angaben uber die Natur des Zuckers mőchte ich noch vertagen. Es gelang mir bis jetzt, etwa $0,2 \mathrm{~g}$ des reinen Osazons $\mathrm{zu}$ isolieren.

Aus diesem allgemeinen Ueberblick durfte trotz der noch vorhandenen Lacken mit Sicher. heit hervorgehen, dass der Aufbau des Zuckers aus Kohlensăure und Wasser lediglich durch Zufuhr von Energie in geeigneter Form gelingt, dass eine kanstliche Assimilation der Kohlensăure ohne Chlorophyll, Chloroplasten, ohne lebende Zelle und ohne Enzyme durchfahrbar ist.

Herr Privatdozent Dr. Jobannes Brode-Berlin:

ÜBER DIE OXYDATION DES STICKSTOFFES IN DER HOCHSPANNUNGSFLAMME.

Wenn sich hochgespannte Elektrizităt in einem regelmässigen Strome von etwa o, 1 Amp. in Luft entlädt, so erfolgt der Ausgleich der Elektrizitat nicht in der Gestalt einer Funkenstrecke oder eines Lichtbogens, sondern in der Form einer Flamme. Diese Hochspannungsflamme ist meines Wissens zuerst von Spotiswoodel) beobachtet, es lassen sich in ihr, wie dieses von Muthmann und Hofer beschrieben ${ }^{2}$ ) ist, drei Zonen beobachten. (Demonstration der Flamme)

Zone I: ein hell leuchtendes, blauliches Lichtband, das nach oben ausgebogen ist;

Zone II: darüber ein breiterer bläulich graner, nach oben strebender Teil, und

Zone III: eine fahl leuchtende, bräunliche, spitz nach oben steigende Schicht.

Das Aussehen der Flamme ist vom Elektrodenmaterial unabhängig; ich benutzte als Elektroden Iridium, Platin und Stifte Nernstscher Glühkorper, das Leuchten lässt sich also nicht auf abgesprengte Teilchen des Elektrodenmateriales zuräckführen. Mit der Stromstărke andert sich

1) Proc. Royal Soc. 30, 174 (1886)

2) Chem. Ber. 36, $43^{8}-453$ (1903). die Flamme nur sehr wenig. Bei Vergrosserung der Elektrodenentfernung nimmt sie grossere Dimensionen an, besonders wăchst Zone III stark an. Wenn diese Flamme in einem abgeschlossenen Luftraume brennt, so verwandelt sich die Luft bis zu einem gewissen Gleichgewicht in nitrose Gase, und umgekehrt wird, wenn wir den Raum, in welchem die Flamme brennt, mit Stickoxyd follen, dieses bis zu dem. selben Gleichgewicht in $\mathrm{N}_{2}$ und $\mathrm{O}_{2}$ zersetzt. Die Gleichgewichtskonzentration an Stickoxyd ist abhangig vom Wattverbrauch der Flamme, der Art des benutzten Stromes, der Elektrodenentfernung, bei kleiner Elektrodenentfernung auch vom Elektrodenmaterial und von kūhlenden Korpern, die wir in die Flamme hineinbringen. Ich will auf diese Verbăltnisse nicht năher ein. gehen, sondern verweise diesbezaglich auf eine von mir verfasste Abhandlung ') und mochte hier nur die Vorgange besprechen, welche sich in den einzelnen Flammenteilen vollziehen. Ueberall wo wir die Erscheinung einer Flamme beobachten, dorfen wir bestimmte Prozesse chemischer oder physikalischer Art annehmen, 